\title{
Association between diet quality, dietary patterns and cardiometabolic health in Australian adults: a cross-sectional study
}

\author{
Katherine M. Livingstone ${ }^{*}$ (iD and Sarah A. McNaughton
}

\begin{abstract}
Background: Diet quality indices score dietary intakes against recommendations, whereas dietary patterns consider the pattern and combination of dietary intakes. Studies evaluating both methodologies in relation to cardiometabolic health in a nationally representative sample are limited. The aim of the present study was to investigate the relationship between diet quality, dietary patterns and markers of cardiometabolic health in Australian adults.

Methods: Dietary data, using two 24-h dietary recalls, were collected from adults in the cross-sectional Australian Health Survey 2011-2013 ( $n=2121 ; 46.4$ (SE 0.48) years). Diet quality was estimated using the Dietary Guideline Index (DGI). Dietary patterns (DPs), derived using reduced rank regression, were estimated using fiber density, SFA: PUFA and total sugars intake as intermediate markers. Multi-variable adjusted linear regression analyses were used to examine associations between diet quality and DPs and blood biomarkers, body mass index, waist circumference, diastolic and systolic blood pressure and an overall cardiometabolic risk score.
\end{abstract}

Results: DGI was associated with lower glucose (coef -0.009 , SE 0.004; P-trend $=0.033$ ), body mass index (coef -0.017 , SE 0.007; P-trend $=0.019$ ) and waist circumference (coef - 0.014, SE 0.005; P-trend =0.008). Two dietary patterns were derived: dietary pattern-1 was characterized by higher intakes of pome fruit and wholegrain bread, while dietary pattern-2 was characterized by higher intakes of added sugars and tropical fruit. Dietary pattern- 1 was associated with lower body mass index (coef - 0.028, SE 0.007; P-trend< 0.001) and waist circumference (coef - 0.017, SE 0.005; $\mathrm{P}$-trend $=0.001$ ). There was a trend towards lower cardiometabolic risk score. Dietary pattern-2 was associated with lower HDL-cholesterol (coef -0.026 , SE 0.012; P-trend $=0.028$ ). There was a trend towards lower diastolic blood pressure. No associations with other markers were observed.

Conclusions: Better diet quality and healthier dietary patterns were primarily associated with favorable anthropometric markers of cardiometabolic health. Findings support the need for comparison of whole-diet based methodologies that take into consideration the interactions between foods and nutrients. Longitudinal studies are warranted to better understand causal relationships between diet and cardiometabolic health.

Keywords: Diet quality, Dietary patterns, Reduced rank regression, Cardiometabolic health, Adults

\footnotetext{
*Correspondence: k.livingstone@deakin.edu.au

Institute for Physical Activity and Nutrition, School of Exercise and Nutrition

Sciences, Deakin University, Melbourne Burwood Campus, 221 Burwood

Highway, Geelong, Victoria 3125, Australia
}

(c) The Author(s). 2018 Open Access This article is distributed under the terms of the Creative Commons Attribution 4.0 International License (http://creativecommons.org/licenses/by/4.0/), which permits unrestricted use, distribution, and reproduction in any medium, provided you give appropriate credit to the original author(s) and the source, provide a link to the Creative Commons license, and indicate if changes were made. The Creative Commons Public Domain Dedication waiver (http://creativecommons.org/publicdomain/zero/1.0/) applies to the data made available in this article, unless otherwise stated. 


\section{Background}

Non-communicable diseases, such as diabetes and cardiovascular disease, are responsible for 40 million deaths per year worldwide [1]. The development of these conditions is mediated through complex biological pathways, such as elevated blood pressure and levels of triglycerides (TAG), total and LDL cholesterol and glucose [2]. With the global health burden of poor cardiometabolic health increasing, a better understanding of major modifiable risk factors, including diet, is needed [3-5].

Research to date has focused primarily on the role of single nutrients and foods in relation to cardiometabolic health $[3,6,7]$. However, given that food and nutrient intakes are often correlated, an increasing body of research is investigating whole diet [8] and its impact on disease risk [9-11]. Whole diet analyses have traditionally been based on data-driven techniques, such as factor analysis, or diet quality indices, estimated according to adherence to dietary guidelines. By combining strengths of both methodologies, reduced rank regression (RRR) uses a priori knowledge of markers of disease risk in a posteriori dietary patterns (DP) derivation [12]. RRR is becoming increasingly used in nutritional epidemiology for deriving DPs and evaluating associations with health outcomes [13-16].

Evidence suggests that better adherence to diet quality indices, such as the Alternate Healthy Eating Index (HEI) $[17,18]$, the Mediterranean diet score [17] and the Dietary Guideline index (DGI) [19], is associated with more favorable levels of many cardiometabolic biomarkers. Findings from a sample of Australian adults showed that a DP, derived using factor analysis and characterized by high consumption of wholegrains and fruit, was associated with higher odds of having a metabolically healthy phenotype [20]. Similarly, in a study of US adults, a RRR-derived DP low in soft drinks and high in wholegrains was inversely associated with TAG [13]. Despite this evidence, few nationally representative studies have compared more than one whole diet measure and few have considered an overall cardiometabolic risk score, nor the moderating effect of body mass index (BMI) [21]. A comparison between diet quality and a novel DP methodologies is needed to strengthen the evidence base for future DP-based policy development [22, 23]. In addition, RRR may better predict risk of disease than purely data-driven DP methodologies [24, 25], yet there is a paucity of research that has examined RRRderived DPs in relation to cardiometabolic health [26].

Therefore, the aim of this study was to examine the relationship between diet quality, using the DGI, and DPs, using RRR, and markers of cardiometabolic health, including BMI, waist circumference (WC), total, HDL and LDL cholesterol, glycated hemoglobin (HbA1c), glucose, TAG, apolipoprotein B, diastolic and systolic blood pressure and an overall cardiometabolic risk score, in the cross-sectional, nationally representative 2011-2013 Australian Health Survey (AHS) [27].

\section{Methods \\ Subjects and study design}

The 2011-13 AHS is a population-based survey that sampled urban and rural households across all Australian states and territories. The AHS consists of two separate surveys (the National Health Survey [NHS] and the National Nutrition and Physical Activity Survey [NNPAS]) and the National Health Measures Survey (NHMS), a third component in which participants from both surveys were invited to participate [27]. In the NHS and NNPAS, 21,108 private dwellings $(n=18,355$ after sample loss in the field stage) and 14,363 private dwellings ( $n=12,366$ after sample loss in the field stage) were selected, respectively. Dietary intakes were estimated in the NNPAS using two, 24-h dietary recalls. Of the 9519 dwellings in the first interview, 7735 (63.6\%) completed the second dietary recall. Anthropometric and blood pressure measures were collected in the NNPAS on a voluntary basis by trained interviewers during home visits. Of the 30,329 respondents aged $\geq 5$ years in the combined sample (NHS and NNPAS), 11,246 (37.1\%) participated in the biomedical component (NHMS). Data relating to fasting tests relate to the fasting population only. For the present analysis individuals were excluded if they i) were pregnant and/or breastfeeding ii) only completed one day of dietary recall and iii) had missing data for outcomes and covariates (Fig. 1). A total of 2121 adults ( $\geq 19 \mathrm{y}$ ) were included in the current analysis. Ethics approval for the NHMS was granted by the Australian Government Department of Health and Ageing Departmental Ethics Committee. Further information on the design and methodologies of these surveys are presented elsewhere [27]. Reporting was conducted in accordance with the STROBE statement (Additional file 1: Table S1).

\section{Study measures \\ Cardiometabolic risk variables}

Weight $(\mathrm{kg})$, height $(\mathrm{cm})$ and WC $(\mathrm{cm})$ measurements were assessed on a voluntary basis by trained interviewers using digital scales, a stadiometer and a metal tape respectively. Waist measurements were taken by placing the tape measure across the top of the belly button. For validation purposes, a random $10 \%$ of respondents were selected to be measured for height and waist an additional time. If this second measurement varied by more than one $\mathrm{cm}$ then a third reading was taken. Weight measurements were only taken once. Subjects were encouraged to remove their shoes and any heavy clothing prior to having measurements taken, although this was not compulsory, and no correction was applied 


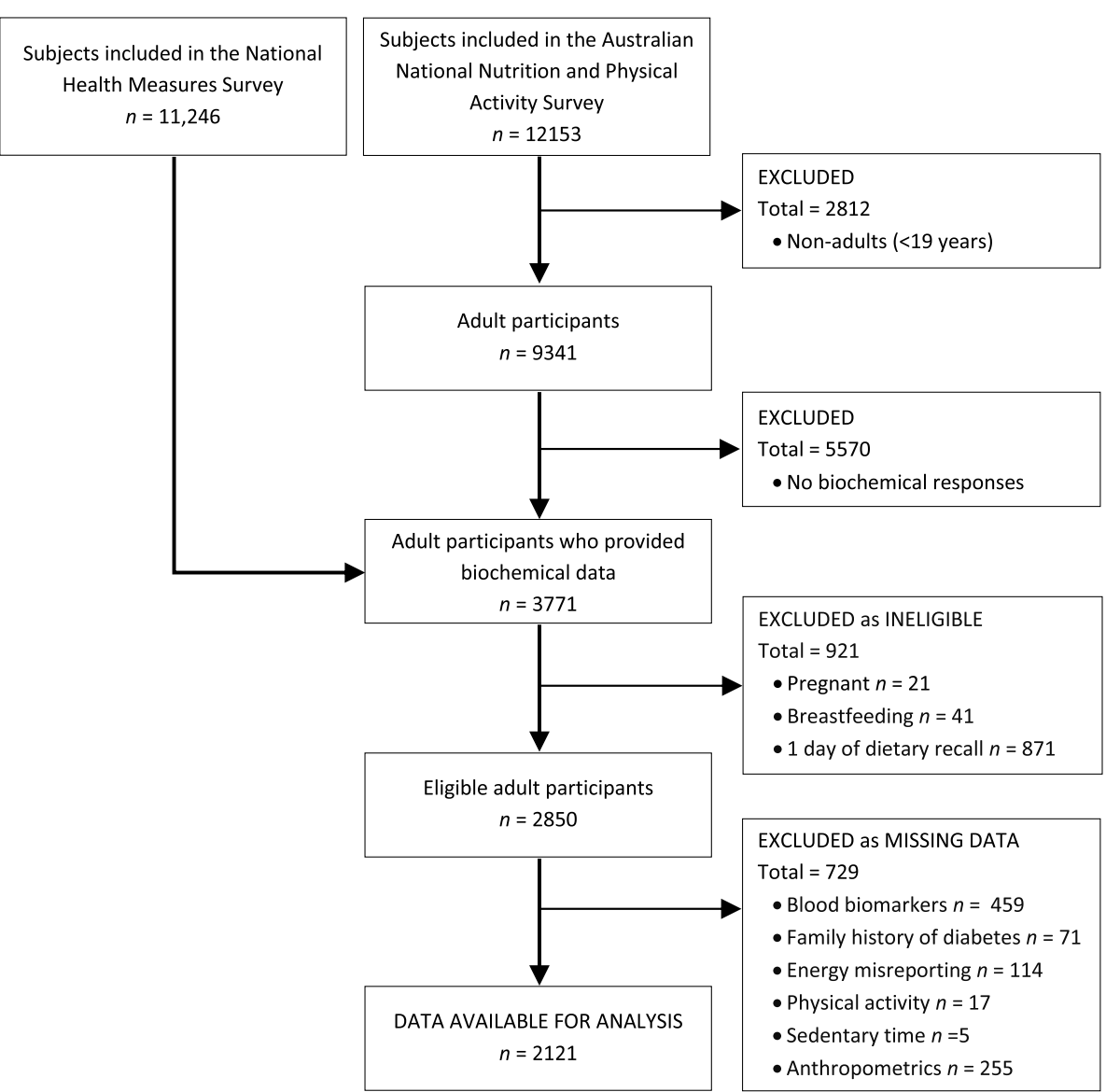

Fig. 1 Flow diagram of subjects included in the cross-sectional analysis of the Australian Health Survey

if they did not. BMI was derived using Quetelet's metric $\left(\mathrm{kg} / \mathrm{m}^{2}\right)$. Standard cut offs were used to derive BMI and WC categories [28].

LDL cholesterol $(\mathrm{mmol} / \mathrm{L})$, TAG $(\mathrm{mmol} / \mathrm{L})$ and plasma glucose $(\mathrm{mmol} / \mathrm{L})$ were measured from blood samples in individuals who reporting fasting for $8 \mathrm{~h}$ or more prior to providing a blood sample [27]. LDL cholesterol was calculated from total cholesterol, HDL cholesterol $(\mathrm{mmol} / \mathrm{L})$ and fasting TAG levels using the Friedewald equation [29]. As recommended by the Australian Bureau of Statistics, individuals with a TAG level of $\geq 4.5 \mathrm{mmol} / \mathrm{L}$ were treated as missing data for the estimation of LDLcholesterol [29]. Apolipoprotein B (g/L), HbA1c (mmol/mol) and total and HDL-cholesterol were measured in biological samples without the need for fasting. Abnormal levels of total, HDL- and LDL-cholesterol were defined as $\geq 5.5 \mathrm{mmol} / \mathrm{L},<1.0 \mathrm{mmol} / \mathrm{L}$ for males and $<1.3 \mathrm{mmol} / \mathrm{L}$ for females and $\geq 3.5 \mathrm{mmol} / \mathrm{L}$, respectively. Abnormal levels of TAG and apolipoprotein $B$ were $\geq 2.0 \mathrm{mmol} / \mathrm{L}$ and $>1.3 \mathrm{mmol} / \mathrm{L}$ for males and $>1.2 \mathrm{mmol} / \mathrm{L}$ for females, respectively. Impaired fasting plasma glucose was defined as $>6.0 \mathrm{mmol} / \mathrm{L}$ and $<7.0 \mathrm{mmol} / \mathrm{L}$, while $\mathrm{HbA} 1 \mathrm{c}$ levels indicative of increased risk of diabetes was defined as 42-47 $\mathrm{mmol} / \mathrm{mol}$ [27]. Diabetes prevalence was estimates by self-reported diabetes diagnosed by a doctor. All analyses were conducted by Douglass Hanly Moir (Australia).

Systolic (SBP) and diastolic blood pressure (DBP) measurements were taken on the left arm. Interviewers performed two blood pressure readings using an automated blood pressure monitor. The second reading was used, unless there was a difference greater than $10 \mathrm{mmHg}$ between the readings, in which case a third reading was taken and the second and third readings were averaged. Data on anti-hypertensive and lipid lowering medication were not recorded [27].

An overall cardiometabolic risk score was derived using WC, TAG, HDL-cholesterol, blood pressure (average blood pressure was used as an index for SBP and DBP), and fasting plasma glucose based on an established methodology [30]. Briefly, all variables were normalized $(\log 10)$ and standardized (i.e. $\mathrm{z}=($ value - mean) $/ \mathrm{SD})$. For HDLcholesterol, the $\mathrm{z}$-score was multiplied by -1 . All z-scores were then summed to compile the cardiometabolic risk score with units of SD. 


\section{Dietary intake}

A 24-h dietary recall was used to provide quantitative information on foods and beverages consumed on the day prior to interview based on the in person USDA Automated Multiple-Pass Method [31]. The interview was divided into five phases: quick list description of food and beverages consumed from midnight to midnight the previous day, prompt the respondent to remember any omitted foods, provide information on time and eating occasion, further details (including preparation method and brand names) and a final probe to recall any omitted foods of beverages [27]. A second 24-h recall, via telephone interview, was collected at least 8 days after the first interview. Only participants who completed both recalls were included in the present analysis. Nutrient intakes were derived from the 24-h recalls using the Australian Supplement and Nutrient Database 2011-13 [32]. Information on the following dietary behaviors were collected in the NNPAS survey: type of milk consumed, usual daily intake of fruit and vegetables and use of salt [27].

\section{Dietary guideline index}

The DGI is a food-based score designed to reflect the diet quality of individuals according to compliance with the 2013 Australian Dietary Guidelines [33]. Dietary intakes of individuals, based on an average of two 24-h recalls and brief questionnaire items, were scored according to ten recommended dietary components (food variety, fruit, vegetables, cereals [total cereals and proportion that is wholegrains], meat and alternatives [total lean meat and alternatives and proportion that is lean], dairy and alternatives and fluid intake [total beverage and proportion that is water]) and six dietary components that should be limited (discretionary foods, SFA, unsaturated fat, added salt, added sugars and alcohol). Further details are presented in Additional file 2: Table S2 and are available elsewhere $[34,35]$.

DGI scores ranged between 0 and 130, with a higher score indicating better diet quality. Each item was scored out of 10, with 0 indicating the guideline was not met. Cut-offs used to obtain the maximum score for each component were tailored to age- and sex- specific foodbased recommendations outlined in the Australian Dietary Guidelines [36]. Proportionate scores were derived where intakes fell between the maximum and minimum scoring criteria for all items except discretionary foods, saturated and unsaturated fat, salt, sugar and alcohol, which scored either 0 or 10 [34, 37, 38].

\section{Dietary patterns}

DPs were determined using RRR is a statistical technique designed to derive DPs that maximize the variation explained by response variables selected based on a priori hypothesis that they are related to the outcome of interest [12]. In the present analyses, fiber density, SFA: PUFA and total sugars intake were selected as response variables. These nutrients were chosen based on evidence from the WHO report on prevention of chronic disease that consumption of dietary fiber, fat and sugars are strongly associated with risk of diabetes and cardiometabolic disease [4, 39]. Recent studies have substantiated the use of these response variables for assessing risk of diabetes [40] and cardiovascular disease [39]. Fiber density was expressed as absolute intake of fiber ( $\mathrm{g} / \mathrm{d}$ ) divided by total daily energy intake (MJ). Percentage energy intake from sugars and fat were calculated by dividing energy intake from sugars $(\mathrm{kJ})$ and fat $(\mathrm{kJ})$ respectively by total energy intake $(\mathrm{kJ})$ and then multiplying by 100 . SFA:PUFA ratio was expressed as the former divided by the latter.

A total of 48 food groups were created for use as predictors in the RRR analyses (Additional file 3: Table S3) to produce the DPs. Based on the AHS food grouping [27], foods were grouped into the following categories: nonalcoholic beverages ( 1 group), cereals ( 7 groups), fats and oils (2 groups), fruit (8 groups), vegetables (8 groups), meat and alternatives (7 groups), dairy (5 groups), soups and sauces (2 groups), snacks and confectionary (4 groups) and alcoholic beverages ( 3 groups). The number of extracted patterns is dependent on the number of response variables, thus intakes $(\mathrm{g} / \mathrm{d})$ of all 48 food groups and the three response variables were used to derive three DPs. These groups were RRR calculated linear functions of food group intakes (dietary patterns) that explained variation in the response variables. A detailed explanation of the RRR methodology can be found elsewhere [12].

To derive a DP score that captured the food groups that contributed most to the RRR pattern, a second, simplified score was derived and used for a sensitivity analysis. This score included food groups with factor loadings greater than $>0.20$ [15] and was generated by summing the standardised food group intakes (z-scores) [41]. The simplified score for DP-1 summed positive loadings for pome fruit, wholegrain bread, wholegrain cereals, nuts and seeds, carrots, brassica vegetables, other vegetables, and negative loadings for fruit drinks, high-fat milk, cream, chocolate and non-wholegrain bread. The simplified score for DP-2 summed positive loadings for added sugars, pome fruit, tropical fruit, other fruit, stone fruit and negative loadings for wine and beer and cider. As the third DP explained less than $10 \%$ of the variation in response variables it was not further investigated and no sensitivity analysis was conducted.

\section{Covariates}

Covariates were identified based on previous literature and via a directed acyclic graph (Additional file 4: Figure S1). Socio-demographic characteristics were collected in the 
NNPAS via interviewer-administered questionnaires. Smoking habits were identified as current, ex-smoker and never smoked. Education status was operationalized as low (completed some high-school or less), medium (completed high-school or completed some high-school and/or certificate/diploma) and high (having a University qualification) [42]. Urban or rural location was defined as major city, inner rural or other [43]. Country of birth was operationalized as born in Australia or another English speaking country (Canada, Ireland, NZ, South Africa, UK, USA) and Other. Information on dieting (currently on a diet to lose weight; currently on a diet for health reasons; currently on a diet to gain weight and not currently on a diet) and atypical dietary intake on day of reporting (much more than usual; usual; much less than usual) were collected. Energy misreporting was calculated as the ratio of energy intake to predicted total energy expenditure (using sex and age-specific equations for a range of weight status, using a physical activity (PA) level of "low active" PA level $>=1.4<1.6$ ) [44]. PA was assessed according to whether participants met recommendations of $150 \mathrm{~min}$ of PA per week and 150 min of PA over 5 or more sessions per week. Time spent sedentary (minutes per day) was defined as sitting or lying down (except when sleeping) for various activities, including time spent sitting at work, and time spent sitting while using computers, watching television, and for other leisure activities. Family history of diabetes was assessed (Yes/No).

\section{Statistical analyses}

Complete case analysis was used (details of missing data are presented in Fig. 1). Variables were tested for skewness and kurtosis and variables with non-normal distributions, which included BMI, WC, sedentary time and all biomarkers, were logarithmically transformed prior to analysis. Values of logarithmically transformed variables were exponentiated to provide geometric means and SE. DPs identified from RRR were categorized into tertiles. When testing for LDL, TAG and glucose, fasting was required and only fasted data were used. Markers of cardiometabolic health markers were treated as categorical or binary outcome variables for the purpose of descriptive statistics and as continuous variables when evaluating associations with dietary intake. Linear regression analyses were used to test for associations between tertiles of diet quality and DP (independent variables) and markers of cardiometabolic health (dependent variables). Analyses were adjusted in Model 1 for age (continuous), sex, smoking (categorical), physical activity (binary), education (categorical), urban or rural location (categorical), energy misreporting (continuous), dieting (categorical) or atypical dietary intake on day of reporting (categorical) and family history of diabetes (binary). Analyses were further adjusted for BMI (continuous) in Model 2 in order to examine the effect independent of BMI. SAS (version 9; SAS Institute, Cary, NC) was used to derive RRR DPs. Data were analyzed using Stata (version 14; StataCorp., College Station, TX, USA). Survey weightings that were calibrated against population benchmarks (i.e. age, sex and area of usual residence) were used to account for the complex survey design. These weightings were specifically designed by the Australian Bureau of Statistics to account for bias associated with those who volunteered to provide biological samples. $P<0.05$ was considered statistically significant. No adjustments were made for multiple comparisons given that analyses were pre-defined and methods were comparable with the available literature [17].

\section{Results}

A total of 2121 individuals were included in the present analyses (men: $n=960$; women: $n=1161$ ) (Fig. 1). Characteristics of the omitted sample with the analytical sample were broadly similar, although slightly more adults who were middle aged, highly educated and living in major cities were included in the analytical sample (Additional file 5: Table S4). A total of $31 \%$ individuals had high total cholesterol, 22\% had low HDL-cholesterol, $31 \%$ had high LDL-cholesterol, $13 \%$ had high triglycerides, $18 \%$ had high apolipoprotein B, 6\% had impaired fasting plasma glucose and $7 \%$ had HbA1c levels indicative of increased risk of diabetes. Five percent of individuals reported having diabetes, while $29 \%$ reported having a family history of diabetes.

\section{Dietary patterns}

The explained variation in food intakes and response variables and the correlations between response variables and DPs are summarized in Table 1 . DP- 1 was positively correlated with fiber density $(r=0.72)$ and inversely correlated with SFA: PUFA $(r=-0.53)$ and total sugars intake $(r=-0.14)$. DP-2 was positively correlated with fiber density $(r=0.31)$, SFA: PUFA $(r=0.24)$ and total sugars intake $(r=0.72)$. As the third DP explained less than $10 \%$ of the variation in response variables it was not further investigated.

Food groups with the top 5 positive and negative factor loadings for DP-1 and DP-2 are presented in Table 2. A full list of factor loadings for both DPs is presented in Additional file 6: Table S5. DP-1 was characterized by higher intakes of pome fruit, wholegrain bread, wholegrain cereals, nuts and seeds and carrot and root vegetables and lower intakes of fruit drinks, full-fat milk, cream, chocolate and non-wholegrain bread. DP-2 was characterized by higher intakes of added sugars, pome fruit, tropical fruit, other fruit and stone fruit and low intakes of wines, beers and ciders, wholegrain cereals, fish and fried vegetables (Table 2). 
Table 1 Explained variation (\%) in food intakes and response variables for each dietary pattern (DP) as assessed using reduced rank regression and correlation coefficient between DP and response variables for cardiometabolic health outcomes $(n=2121)^{a}$

\begin{tabular}{|c|c|c|c|c|c|c|c|c|}
\hline \multirow[t]{2}{*}{ DP } & \multicolumn{5}{|c|}{ Explained variation (\%) } & \multicolumn{3}{|c|}{ Correlation coefficient ${ }^{b, c}$} \\
\hline & Food intakes (total) & Responses (total) & Fibre density (g/MJ) & SFA:PUFA & Sugars (\%E) & Fibre density (g/MJ) & SFA: PUFA & Sugars (\%E) \\
\hline$\overline{D P}-1$ & 3.94 & 26.9 & 50.9 & 27.5 & 2.23 & $0.72^{* * *}$ & $-0.53^{* * *}$ & $-0.26^{* * *}$ \\
\hline DP-2 & 2.51 & 21.0 & 60.0 & 31.9 & 51.8 & $0.30^{* * *}$ & $0.24^{* * *}$ & $0.72^{* * *}$ \\
\hline DP-3 & 2.47 & 7.99 & 65.4 & 46.0 & 56.3 & $0.24^{* * *}$ & $0.36^{* * *}$ & $-0.20^{* *}$ \\
\hline
\end{tabular}

${ }^{a} D P$ dietary pattern, SFA saturated fatty acid, $P U F A$ poly-unsaturated fatty acid, \%E percentage energy

$b^{* * * *}$ Denotes correlation coefficient is significant at $P<0.001$

$c^{* *}$ Denotes correlation coefficient is significant at $P<0.01$

\section{Diet quality, dietary patterns and demographic characteristics}

As shown in Table 3, those individuals with higher DGI were more highly educated, smoked less and were more physically active. Higher DGI scores were associated with higher DP-1 and DP-2 scores, greater fiber density and lower SFA: PUFA ratios. Participants with higher DP-1 scores were older, more physically active, had higher HbA1c levels and higher SBP, while those with higher DP-2 score smoked less and had lower HDLcholesterol levels (Additional file 7: Table S6).

\section{Diet quality, dietary patterns and cardiometabolic health}

Higher DGI was associated with lower plasma glucose levels, BMI and WC. No other significant associations between DGI and cardiometabolic markers were observed. Following adjustment for BMI, the relationship between DGI and plasma glucose was attenuated but remained significant (Table 4).

Higher DP-1 was associated with lower BMI and WC (Table 5). Higher DP-2 was associated with lower HDL-C. There was a trend towards lower DBP. Following adjustment for BMI, the relationship between DP-2 and HDLcholesterol was attenuated but remained significant and the association with DBP became significant (Table 6). No associations between DPs and other markers were observed.

\section{Sensitivity analyses}

Patterns of significant results remained consistent when associations between simplified DP scores and cardiometabolic health were investigated. Simplified DP-1 was associated with lower BMI (coef - 0.023, SE 0.009; P-trend = 0.012 ) and WC (coef -0.014, SE 0.006; P-trend =0.023) following adjustment for Model 1. Simplified DP-2 was associated with lower HDL-cholesterol (coef -0.033, SE 0.010; P-trend $=0.001$ ) and DBP (coef - 1.277, SE 0.418; P-trend $=0.003$ ) following adjustment for Model 2 .

\section{Discussion}

The aim of this study was to investigate the relationship between DPs, diet quality and cardiometabolic health in a nationally-representative sample of Australian adults. Our main findings are that both higher diet quality and a healthier DP (DP1) were primarily associated with favorable anthropometric markers of cardiometabolic health (BMI, WC) independent of numerous potential demographic and health-related confounders. Although effect sizes were small, these findings highlight the consistency of a diet quality and DP methodology to estimate associations with anthropometric markers of cardiometabolic health. Previous studies have independently compared diet quality scores [17] and DP methodologies [20] with markers of cardiometabolic health. However, few studies simultaneously compare multiple measures of overall diet with cardiometabolic health.

Evidence for an association between diet quality and markers of cardiometabolic health is mixed. Consistent with our findings, in a sample of Hispanic adults, higher 2010 Alternative HEI was associated with lower WC and glucose levels [18]. Moreover, studies in Australian adult populations have shown that higher DGI was associated with lower glucose levels [19, 45]. However, given the strength of the association between DGI and glucose levels observed in our study, we cannot discount the possibility of this being a chance finding. In line with a recent cross-sectional study of multiple diet quality scores in US women (predominantly Caucasian) [17], but in contrast with findings for the 2005 HEI (50\% Caucasian) [46], diet quality was not associated with total or HDL-cholesterol. Similar inconsistencies are evident for other markers, such as TAG and HbA1c [46]. The inconsistency of associations with markers of cardiometabolic health may be partly attributable to differences in the ethnicity of the sample population [47], given that $80 \%$ of our sample were born in Australia or another English speaking country. However, it is likely to largely be due to methodological differences, such as reverse causation given the cross-sectional design, the method of assessing diet quality, choice of covariates and variation in sample sizes and resulting statistical power. To mitigate individual differences in markers, we evaluated an overall cardiometabolic risk score. This score has been used primarily for dietary behaviours [48] rather than patterns and so warrants further investigation.

The role of DPs in relation to cardiometabolic health is mixed, with only a small number of studies utilizing RRR [13, 49-51]. Of these studies, some have used 
Table 2 Intakes of response variables and key foods across sex-specific tertiles (T) of dietary pattern $(n=2121)^{a}$

\begin{tabular}{|c|c|c|c|c|c|}
\hline \multirow[t]{2}{*}{ Food groups } & \multirow[t]{2}{*}{ Factor loading } & \multicolumn{3}{|c|}{ Tertile of dietary pattern } & \multirow[t]{2}{*}{$P$-trend } \\
\hline & & $\mathrm{T} 1$ & $\mathrm{~T} 2$ & T3 & \\
\hline \multicolumn{6}{|l|}{ DP-1 } \\
\hline \multicolumn{6}{|l|}{ Response variables } \\
\hline Fibre density, g/MJ & - & $2.10 \pm 0.04$ & $2.75 \pm 0.04$ & $3.79 \pm 0.06$ & $<0.001$ \\
\hline SFA: PUFA & - & $3.55 \pm 0.09$ & $2.53 \pm 0.06$ & $1.99 \pm 0.06$ & $<0.001$ \\
\hline Sugar, \%E & - & $20.7 \pm 0.42$ & $17.7 \pm 0.33$ & $18.7 \pm 0.37$ & $<0.001$ \\
\hline \multicolumn{6}{|l|}{ Direct associations, g/d } \\
\hline Pome fruit & 0.23 & $51 \pm 6$ & $88 \pm 11$ & $161 \pm 12$ & $<0.001$ \\
\hline Wholegrain bread & 0.22 & $33 \pm 5$ & $45 \pm 3$ & $82 \pm 4$ & $<0.001$ \\
\hline Wholegrain cereals & 0.22 & $31 \pm 4$ & $39 \pm 3$ & $72 \pm 5$ & $<0.001$ \\
\hline Nuts and seeds & 0.22 & $9 \pm 1$ & $13 \pm 1$ & $29 \pm 4$ & $<0.001$ \\
\hline Carrot and root vegetables & 0.21 & $29 \pm 3$ & $32 \pm 3$ & $72 \pm 8$ & $<0.001$ \\
\hline \multicolumn{6}{|l|}{ Inverse associations } \\
\hline Fruit drinks & -0.24 & $547 \pm 46$ & $283 \pm 40$ & $158 \pm 17$ & $<0.001$ \\
\hline Full fat milk & -0.24 & $447 \pm 34$ & $244 \pm 20$ & $189 \pm 19$ & $<0.001$ \\
\hline Cream & -0.22 & $77 \pm 8$ & $33 \pm 5$ & $20 \pm 3$ & $<0.001$ \\
\hline Chocolate & -0.21 & $23 \pm 2$ & $8 \pm 1$ & $6 \pm 1$ & $<0.001$ \\
\hline Non-wholegrain bread & -0.20 & $138 \pm 9$ & $108 \pm 8$ & $82 \pm 6$ & $<0.001$ \\
\hline \multicolumn{6}{|l|}{ DP-2 } \\
\hline \multicolumn{6}{|l|}{ Response variables } \\
\hline Fibre density, g/MJ & - & $2.52 \pm 0.06$ & $2.90 \pm 0.05$ & $3.21 \pm 0.07$ & $<0.001$ \\
\hline SFA: PUFA & - & $2.32 \pm 0.07$ & $2.70 \pm 0.07$ & $3.07 \pm 0.08$ & $<0.001$ \\
\hline Sugar, \%E & - & $13.9 \pm 0.28$ & $18.5 \pm 0.37$ & $24.7 \pm 0.30$ & $<0.001$ \\
\hline \multicolumn{6}{|l|}{ Direct associations, g/d } \\
\hline Added sugars & 0.31 & $24 \pm 2$ & $34 \pm 3$ & $53 \pm 4$ & $<0.001$ \\
\hline Pome fruit & 0.28 & $52 \pm 6$ & $83 \pm 8$ & $165 \pm 11$ & $<0.001$ \\
\hline Tropical fruit & 0.24 & $45 \pm 4$ & $70 \pm 6$ & $110 \pm 8$ & $<0.001$ \\
\hline Other fruit & 0.21 & $28 \pm 3$ & $50 \pm 6$ & $77 \pm 9$ & $<0.001$ \\
\hline Stone fruit & 0.20 & $18 \pm 3$ & $27 \pm 4$ & $86 \pm 10$ & $<0.001$ \\
\hline \multicolumn{6}{|l|}{ Inverse associations, $\mathrm{g} / \mathrm{d}$} \\
\hline Wines & -0.30 & $281 \pm 27$ & $99 \pm 13$ & $60 \pm 10$ & $<0.001$ \\
\hline Beers and ciders & -0.30 & $478 \pm 54$ & $187 \pm 33$ & $67 \pm 13$ & $<0.001$ \\
\hline Non-wholegrain cereals & -0.19 & $284 \pm 29$ & $200 \pm 23$ & $135 \pm 13$ & $<0.001$ \\
\hline Fish & -0.17 & $70 \pm 8$ & $39 \pm 5$ & $26 \pm 3$ & $<0.001$ \\
\hline Fried vegetables & -0.15 & $28 \pm 5$ & $21 \pm 6$ & $14 \pm 3$ & 0.035 \\
\hline
\end{tabular}

${ }^{a} D P$ dietary pattern, SFA saturated fatty acid, PUFA poly-unsaturated fatty acid, \%E percentage energy; Values represent mean \pm SE after adjustment for survey weighting

${ }^{b}$ Linear regression analyses tested for trends across tertiles of dietary pattern. Analyses were adjusted for age and sex

biochemical response variables, such as cholesterol, to derive associations between DPs and markers of cardiovascular health [25] and risk [13]. Associations observed between DP-1, consistent with a 'healthy' DP, and anthropometric outcomes are comparable to other studies $[20,25,52-54]$. In a recent analysis of 10,008 individuals from the Multiethnic Cohort, a RRR-derived DP (using four biomarkers as response variables) and low in fruit drinks and white rice and high in whole grains and fruits was inversely associated with BMI [13]. Few studies have use nutrient intakes as response variables. In a longitudinal study of 2037 Swedish adults, an 'unhealthy' RRR-derived DP characterized by some similar response variables to our study (high dietary energy density, SFA and low fiber-density) was associated with greater adiposity, cholesterol, TAG, SBP and DBP but not with 
Table 3 Dietary, demographic and cardiometabolic characteristics of Australian adults across sex-specific tertiles (T) of diet quality $(n=2121)^{a}$

\begin{tabular}{|c|c|c|c|c|c|}
\hline \multirow[t]{2}{*}{ Characteristic } & \multirow[t]{2}{*}{ All } & \multicolumn{3}{|l|}{ Diet quality } & \multirow[t]{2}{*}{$P$-trend ${ }^{b}$} \\
\hline & & $\mathrm{T1}$ & $\mathrm{T} 2$ & T3 & \\
\hline \multicolumn{6}{|l|}{ Dietary } \\
\hline DGl & $81.8 \pm 0.58$ & $67.0 \pm 0.49$ & $82.1 \pm 0.21$ & $96.2 \pm 0.41$ & $<0.001$ \\
\hline Dietary pattern 1 & $0.07 \pm 0.04$ & $-0.58 \pm 0.06$ & $0.07 \pm 0.07$ & $0.72 \pm 0.06$ & $<0.001$ \\
\hline Dietary pattern 2 & $0.01 \pm 0.04$ & $-0.31 \pm 0.06$ & $0.10 \pm 0.05$ & $0.24 \pm 0.06$ & $<0.001$ \\
\hline Fibre density, g/MJ & $2.87 \pm 0.04$ & $2.23 \pm 0.04$ & $2.85 \pm 0.06$ & $3.54 \pm 0.07$ & $<0.001$ \\
\hline SFA: PUFA & $2.69 \pm 0.05$ & $2.89 \pm 0.09$ & $2.72 \pm 0.08$ & $2.47 \pm 0.07$ & $<0.001$ \\
\hline Sugar, \%E & $19.0 \pm 0.24$ & $18.2 \pm 0.40$ & $19.5 \pm 0.37$ & $19.4 \pm 0.39$ & 0.054 \\
\hline \multicolumn{6}{|l|}{ Demographic } \\
\hline Age, y & $46.4 \pm 0.48$ & $44.3 \pm 1.20$ & $47.1 \pm 0.95$ & $47.7 \pm 1.29$ & 0.11 \\
\hline Female, \% & 49.8 & 47.4 & 48.5 & 53.6 & 0.27 \\
\hline Country of birth (English speaking) & 79.8 & 82.2 & 78.4 & 78.9 & 0.51 \\
\hline \multicolumn{6}{|l|}{ Highest level of education } \\
\hline Low & 19.5 & 22.9 & 18.5 & 17.1 & \multirow[t]{3}{*}{0.025} \\
\hline Medium & 49.6 & 51.6 & 52.0 & 45.2 & \\
\hline High & 30.9 & 25.5 & 29.6 & 37.7 & \\
\hline \multicolumn{6}{|l|}{ Smoking, \% } \\
\hline Current smoker & 11.9 & 18.1 & 11.9 & 5.81 & \multirow[t]{3}{*}{$<0.001$} \\
\hline Former smoker & 33.4 & 37.1 & 32.6 & 30.3 & \\
\hline Never smoked & 54.7 & 44.8 & 55.5 & 63.9 & \\
\hline Meet PA recommendations, \% & 50.2 & 42.8 & 53.5 & 54.3 & 0.036 \\
\hline Sedentary time, min/d & $343 \pm 5.8$ & $350 \pm 10.2$ & $336 \pm 11.2$ & $344 \pm 8.43$ & 0.64 \\
\hline \multicolumn{6}{|l|}{ Cardiometabolic } \\
\hline $\mathrm{HbA} 1 \mathrm{c}, \mathrm{mmol} / \mathrm{mol}$ & $35.6 \pm 0.20$ & $35.6 \pm 0.32$ & $35.9 \pm 0.30$ & $35.4 \pm 0.36$ & 0.71 \\
\hline Plasma glucose, mmol/L & $5.08 \pm 0.02$ & $5.12 \pm 0.04$ & $5.12 \pm 0.04$ & $5.00 \pm 0.04$ & 0.050 \\
\hline Total cholesterol, mmol/L & $5.00 \pm 0.04$ & $5.00 \pm 0.05$ & $5.00 \pm 0.07$ & $5.00 \pm 0.05$ & 0.88 \\
\hline HDL cholesterol, mmol/L & $1.35 \pm 0.12$ & $1.35 \pm 0.02$ & $1.36 \pm 0.02$ & $1.34 \pm 0.02$ & 0.57 \\
\hline LDL cholesterol, mmol/L & $3.08 \pm 0.03$ & $3.07 \pm 0.05$ & $3.08 \pm 0.06$ & $3.08 \pm 0.04$ & 0.72 \\
\hline Triglycerides, mmol/L & $1.23 \pm 0.02$ & $1.23 \pm 0.04$ & $1.20 \pm 0.04$ & $1.27 \pm 0.04$ & 0.76 \\
\hline Apolipoprotein B, g/L & $1.00 \pm 0.01$ & $1.00 \pm 0.18$ & $1.00 \pm 0.02$ & $1.01 \pm 0.01$ & 0.29 \\
\hline $\mathrm{BMI}, \mathrm{kg} / \mathrm{m}^{2}$ & $27.0 \pm 0.19$ & $27.4 \pm 0.34$ & $26.7 \pm 0.32$ & $26.8 \pm 0.35$ & 0.23 \\
\hline \multicolumn{6}{|l|}{ BMl category, \% } \\
\hline Underweight/normal weight & 40.4 & 38.1 & 39.4 & 43.7 & \multirow[t]{3}{*}{0.32} \\
\hline Overweight & 35.1 & 33.7 & 36.4 & 35.1 & \\
\hline Obese & 24.5 & 28.2 & 24.2 & 21.2 & \\
\hline Waist circumference, cm & $91.3 \pm 0.46$ & $92.6 \pm 0.91$ & $91.0 \pm 0.90$ & $90.3 \pm 0.94$ & 0.14 \\
\hline Systolic blood pressure, $\mathrm{mmHg}$ & $121 \pm 0.58$ & $120 \pm 1.11$ & $121 \pm 1.10$ & $122 \pm 1.18$ & 0.36 \\
\hline Diastolic blood pressure, $\mathrm{mmHg}$ & $75.6 \pm 0.39$ & $75.4 \pm 0.75$ & $75.4 \pm 0.62$ & $76.0 \pm 0.84$ & 0.65 \\
\hline Overall cardiometabolic risk score & $-0.11 \pm 0.02$ & $-0.10 \pm 0.04$ & $-0.11 \pm 0.04$ & $-0.12 \pm 0.04$ & 0.69 \\
\hline
\end{tabular}

${ }^{\mathrm{a} B M I}$ body mass index, DP dietary pattern; Education: low (completed some high-school or less), medium (completed high-school or completed some high-school and/or certificate/diploma) and high (having a tertiary qualification). BMl category: underweight/normal weight $\left(\mathrm{BMl}<25 \mathrm{~kg} / \mathrm{m}^{2}\right)$, overweight $\left(25 \leq \mathrm{BMl}<30 \mathrm{~kg} / \mathrm{m}^{2}\right)$, obese $\left(\mathrm{BMI} \geq 30 \mathrm{~kg} / \mathrm{m}^{2}\right)$; Overall cardiometabolic risk score was based on WC, TAG, HDL-cholesterol, blood pressure (average blood pressure was used as an index for systolic and diastolic blood pressure), and fasting plasma glucose based on an established methodology [30]. Values represent mean \pm SE after adjustment for survey weighting. Where transformed for regression analyses, values represent exponentiated geometric mean $\pm \mathrm{SE}$

${ }^{b}$ Linear regression analyses (continuous variables) and $x^{2}$ (categorical variables) were used to test for trends across tertiles 
Table 4 Multivariable adjusted regression coefficients for cardiometabolic risk markers per sex-specific tertiles (T) of dietary guideline index (DGI) $(n=2121)^{\mathrm{a}}$

\begin{tabular}{|c|c|c|c|c|}
\hline \multirow[t]{2}{*}{ Characteristic } & \multicolumn{3}{|c|}{ Tertile of DGI } & \multirow[t]{2}{*}{$P$-trend } \\
\hline & $\mathrm{T1}$ & $\mathrm{T} 2$ & T3 & \\
\hline \multicolumn{5}{|c|}{$\mathrm{HbA1c}(\mathrm{mmol} / \mathrm{mol})$} \\
\hline Model 1 & ref & $0.001(0.008)$ & $-0.004(0.010)$ & 0.70 \\
\hline Model 2 & ref & $0.004(0.010)$ & $-0.001(0.010)$ & 0.90 \\
\hline \multicolumn{5}{|c|}{ Plasma glucose (mmol/L) } \\
\hline Model 1 & ref & $-0.004(0.009)$ & $-0.024(0.009)$ & 0.008 \\
\hline Model 2 & ref & $0.001(0.009)$ & $-0.019(0.009)$ & 0.033 \\
\hline \multicolumn{5}{|c|}{ Total cholesterol (mmol/L) } \\
\hline Model 1 & ref & $-0.001(0.016)$ & $-0.004(0.017)$ & 0.82 \\
\hline Model 2 & ref & $0.004(0.016)$ & $-0.003(0.017)$ & 0.98 \\
\hline \multicolumn{5}{|c|}{ HDL cholesterol (mmol/L) } \\
\hline Model 1 & ref & $-0.003(0.021)$ & $-0.029(0.023)$ & 0.20 \\
\hline Model 2 & ref & $-0.014(0.020)$ & $-0.041(0.023)$ & 0.08 \\
\hline \multicolumn{5}{|c|}{ LDL cholesterol (mmol/L) } \\
\hline Model 1 & ref & $0.008(0.023)$ & $0.002(0.025)$ & 0.93 \\
\hline Model 2 & ref & $0.014(0.022)$ & $0.009(0.025)$ & 0.73 \\
\hline \multicolumn{5}{|c|}{ Triglycerides (mmol/L) } \\
\hline Model 1 & ref & $-0.020(0.043)$ & $0.025(0.033)$ & 0.44 \\
\hline Model 2 & ref & $0.002(0.041)$ & $0.047(0.034)$ & 0.17 \\
\hline \multicolumn{5}{|c|}{ Apolipoprotein B (g/L) } \\
\hline Model 1 & ref & $0.021(0.024)$ & $0.033(0.025)$ & 0.20 \\
\hline Model 2 & ref & $0.030(0.023)$ & $0.043(0.025)$ & 0.10 \\
\hline \multicolumn{5}{|l|}{ BMI $\left(\mathrm{kg} / \mathrm{m}^{2}\right)$} \\
\hline Model 1 & ref & $-0.033(0.015)$ & $-0.033(0.014)$ & 0.019 \\
\hline Model 2 & - & - & - & - \\
\hline \multicolumn{5}{|c|}{ Waist circumference $(\mathrm{cm})$} \\
\hline Model 1 & ref & $-0.022(0.013)$ & $-0.028(0.010)$ & 0.008 \\
\hline Model 2 & - & - & - & - \\
\hline \multicolumn{5}{|c|}{ Systolic blood pressure (mmHg) } \\
\hline Model 1 & ref & $-0.642(1.153)$ & $0.329(1.591)$ & 0.83 \\
\hline Model 2 & ref & $-0.164(1.120)$ & $0.805(1.591)$ & 0.61 \\
\hline \multicolumn{5}{|c|}{ Diastolic blood pressure (mmHg) } \\
\hline Model 1 & ref & $-0.494(0.834)$ & $-0.076(1.161)$ & 0.95 \\
\hline Model 2 & ref & $0.078(0.765)$ & $0.495(1.160)$ & 0.67 \\
\hline \multicolumn{5}{|c|}{ Overall cardiometabolic risk score } \\
\hline Model 1 & ref & $-0.044(0.050)$ & $-0.030(0.041)$ & 0.48 \\
\hline Model 2 & - & - & - & - \\
\hline
\end{tabular}

${ }^{\mathrm{a} B M I}$ body mass index, Values represent regression coefficients and SE. Overall cardiometabolic risk score was based on WC, TAG, HDL-cholesterol, blood pressure (average blood pressure was used as an index for systolic and diastolic blood pressure), and fasting plasma glucose based on an established methodology [30]

bLinear regression analyses were used to test for significant differences across tertiles of diet quality score. Analyses were adjusted for Model 1 and Model 2. Model 1 adjusted for age (continuous), sex, smoking (categorical), physical activity (binary), education (categorical), urban or rural location (categorical), energy misreporting (continuous), dieting (categorical) or atypical dietary intake on day of reporting (categorical) and family history of diabetes. Blood biomarkers and blood pressure outcomes were further adjusted for BMI in Model 2
Table 5 Multivariable adjusted regression coefficients for cardiometabolic risk markers per sex-specific tertiles (T) of dietary pattern $1(n=2121)^{a}$

\begin{tabular}{|c|c|c|c|c|}
\hline \multirow[t]{2}{*}{ Characteristic } & \multicolumn{3}{|c|}{ Tertile of dietary pattern } & \multirow[t]{2}{*}{$P$-trend } \\
\hline & $\mathrm{T1}$ & $\mathrm{T} 2$ & T3 & \\
\hline \multicolumn{5}{|c|}{$\mathrm{HbA1c}(\mathrm{mmol} / \mathrm{mol})$} \\
\hline Model 1 & ref & $0.008(0.007)$ & $0.004(0.001)$ & 0.26 \\
\hline Model 2 & ref & $0.007(0.010)$ & $0.020(0.013)$ & 0.13 \\
\hline \multicolumn{5}{|c|}{ Plasma glucose (mmol/L) } \\
\hline Model 1 & ref & $-0.017(0.001)$ & $-0.007(0.010)$ & 0.52 \\
\hline Model 2 & ref & $-0.010(0.008)$ & $0.002(0.010)$ & 0.84 \\
\hline \multicolumn{5}{|c|}{ Total cholesterol (mmol/L) } \\
\hline Model 1 & ref & $-0.020(0.016)$ & $-0.022(0.019)$ & 0.26 \\
\hline Model 2 & ref & $-0.015(0.016)$ & $-0.017(0.019)$ & 0.40 \\
\hline
\end{tabular}

HDL cholesterol (mmol/L)

$\begin{array}{lllll}\text { Model } 1 & \text { ref } & 0.032(0.021) & 0.003(0.020) & 0.93 \\ \text { Model } 2 & \text { ref } & 0.017(0.022) & -0.016(0.019) & 0.37\end{array}$

LDL cholesterol ( $\mathrm{mmol} / \mathrm{L})$

$\begin{array}{lllll}\text { Model } 1 & \text { ref } & -0.035(0.023) & -0.027(0.029) & 0.37 \\ \text { Model } 2 & \text { ref } & -0.027(0.024) & -0.016(0.028) & 0.58\end{array}$

Triglycerides $(\mathrm{mmol} / \mathrm{L})$

$\begin{array}{lllll}\text { Model } 1 & \text { ref } & -0.063(0.032) & -0.067(0.036) & 0.07 \\ \text { Model } 2 & \text { ref } & -0.031(0.033) & -0.030(0.035) & 0.41\end{array}$

Apolipoprotein B (g/L)

$\begin{array}{lllll}\text { Model } 1 & \text { ref } & -0.041(0.025) & -0.022(0.028) & 0.46 \\ \text { Model } 2 & \text { ref } & -0.027(0.025) & -0.005(0.026) & 0.88\end{array}$

\section{BMI $\left(\mathrm{kg} / \mathrm{m}^{2}\right)$}

$\begin{array}{cccll}\text { Model } 1 & \text { ref } & -0.048(0.012) & -0.056(0.015) & <0.001 \\ \text { Model } 2 & - & - & - & - \\ \text { Waist circumference }(\mathrm{cm}) & & & \end{array}$

$\begin{array}{lllll}\text { Model } 1 & \text { ref } & -0.032(0.009) & -0.035(0.010) & 0.001 \\ \text { Model } 2 & - & - & - & -\end{array}$

Systolic blood pressure $(\mathrm{mmHg})$

$\begin{array}{lcccc}\text { Model } 1 & \text { ref } & 1.431(1.132) & 0.753(1.376) & 0.61 \\ \text { Model 2 } & \text { ref } & 2.132(1.091) & 1.571(1.286) & 0.25 \\ \text { Diastolic blood pressure }(\mathrm{mmHg}) & & \\ \text { Model 1 } & \text { ref } & 0.708(0.879) & -0.566(1.024) & 0.56 \\ \text { Model 2 } & \text { ref } & 1.530(0.850) & 0.394(1.004) & 0.74\end{array}$

Overall cardiometabolic risk score

\begin{tabular}{lllll} 
Model 1 & ref & $-0.097(0.038)$ & $-0.082(0.042)$ & 0.061 \\
Model 2 & - & - & - & - \\
\hline
\end{tabular}

${ }^{\mathrm{a} B M I}$ body mass index; Values represent regression coefficients and SE. Overall cardiometabolic risk score was based on WC, TAG, HDL-cholesterol, blood pressure (average blood pressure was used as an index for systolic and diastolic blood pressure), and fasting plasma glucose based on an established methodology [30]

${ }^{b}$ Linear regression analyses were used to test for significant differences across tertiles of dietary pattern score. Analyses were adjusted for Model 1 and Model 2. Model 1 adjusted for age (continuous), sex, smoking (categorical), physical activity (binary), education (categorical), urban or rural location (categorical), energy misreporting (continuous), dieting (categorical) or atypical dietary intake on day of reporting (categorical) and family history of diabetes. Blood biomarkers and blood pressure outcomes were further adjusted for BMI in Model 2 
Table 6 Multivariable adjusted regression coefficients for cardiometabolic risk markers per sex-specific tertiles ( $T$ ) of dietary pattern $2(n=2121)^{a}$

\begin{tabular}{|c|c|c|c|c|}
\hline \multirow[t]{2}{*}{ Characteristic } & \multicolumn{3}{|c|}{ Tertile of dietary pattern } & \multirow[t]{2}{*}{$P$-trend ${ }^{b}$} \\
\hline & $\mathrm{T1}$ & $\mathrm{T} 2$ & T3 & \\
\hline \multicolumn{5}{|c|}{$\mathrm{HbA1c}(\mathrm{mmol} / \mathrm{mol})$} \\
\hline Model 1 & ref & $-0.003(0.010)$ & $0.008(0.009)$ & 0.37 \\
\hline Model 2 & ref & $-0.004(0.009)$ & $0.007(0.009)$ & 0.44 \\
\hline \multicolumn{5}{|c|}{ Plasma glucose (mmol/L) } \\
\hline Model 1 & ref & $-0.009(0.008)$ & $-0.007(0.008)$ & 0.35 \\
\hline Model 2 & ref & $-0.019(0.008)$ & $-0.009(0.007)$ & 0.24 \\
\hline \multicolumn{5}{|c|}{ Total cholesterol (mmol/L) } \\
\hline Model 1 & ref & $-0.033(0.018)$ & $-0.009(0.017)$ & 0.62 \\
\hline Model 2 & ref & $-0.033(0.018)$ & $-0.010(0.017)$ & 0.57 \\
\hline \multicolumn{5}{|c|}{ HDL cholesterol (mmol/L) } \\
\hline Model 1 & ref & $-0.035(0.022)$ & $-0.056(0.024)$ & 0.022 \\
\hline Model 2 & ref & $-0.034(0.021)$ & $-0.053(0.023)$ & 0.028 \\
\hline \multicolumn{5}{|c|}{ LDL cholesterol (mmol/L) } \\
\hline Model 1 & ref & $-0.023(0.027)$ & $0.014(0.026)$ & 0.57 \\
\hline Model 2 & ref & $-0.024(0.026)$ & $0.012(0.025)$ & 0.61 \\
\hline \multicolumn{5}{|c|}{ Triglycerides (mmol/L) } \\
\hline Model 1 & ref & $-0.063(0.041)$ & $-0.018(0.040)$ & 0.69 \\
\hline Model 2 & ref & $-0.064(0.042)$ & $-0.024(0.040)$ & 0.56 \\
\hline \multicolumn{5}{|c|}{ Apolipoprotein B (g/L) } \\
\hline Model 1 & ref & $-0.026(0.026)$ & $0.013(0.025)$ & 0.57 \\
\hline Model 2 & ref & $-0.026(0.025)$ & $0.010(0.023)$ & 0.64 \\
\hline \multicolumn{5}{|l|}{ BMI $\left(\mathrm{kg} / \mathrm{m}^{2}\right)$} \\
\hline Model 1 & ref & $0.001(0.016)$ & $0.010(0.014)$ & 0.49 \\
\hline Model 2 & - & - & - & - \\
\hline \multicolumn{5}{|c|}{ Waist circumference $(\mathrm{cm})$} \\
\hline Model 1 & ref & $-0.003(0.012)$ & $0.002(0.010)$ & 0.84 \\
\hline Model 2 & - & - & - & - \\
\hline \multicolumn{5}{|c|}{ Systolic blood pressure (mmHg) } \\
\hline Model 1 & ref & $1.885(1.286)$ & $-0.435(1.090)$ & 0.67 \\
\hline Model 2 & ref & $1.871(1.298)$ & $-0.573(1.051)$ & 0.57 \\
\hline \multicolumn{5}{|c|}{ Diastolic blood pressure $(\mathrm{mmHg})$} \\
\hline Model 1 & ref & $0.275(0.871)$ & $-1.811(0.969)$ & 0.07 \\
\hline Model 2 & ref & $0.258(0.818)$ & $-1.979(0.908)$ & 0.033 \\
\hline \multicolumn{5}{|c|}{ Overall cardiometabolic risk score } \\
\hline Model 1 & ref & $0.002(0.044)$ & $0.010(0.046)$ & 0.83 \\
\hline Model 2 & - & - & - & - \\
\hline
\end{tabular}

${ }^{\mathrm{a} B M I}$, body mass index; Values represent regression coefficients and SE. Overall cardiometabolic risk score was based on WC, TAG, HDL-cholesterol, blood pressure (average blood pressure was used as an index for systolic and diastolic blood pressure), and fasting plasma glucose based on an established methodology [30]

bLinear regression analyses were used to test for significant differences across tertiles of dietary pattern score. Analyses were adjusted for Model 1 and Model 2. Model 1 adjusted for age (continuous), sex, smoking (categorical), physical activity (binary), education (categorical), urban or rural location (categorical), energy misreporting (continuous), dieting (categorical) or atypical dietary intake on day of reporting (categorical) and family history of diabetes. Blood biomarkers and blood pressure outcomes were further adjusted for BMI in Model 2
CVD endpoints [52]. However, comparability of results was limited as this study was conducted in obese individuals only, who may be more metabolically sensitive to an 'unhealthy' diet [55]. Recent data from a AHS study showed that a 'healthy' DP, derived using factor analysis and characterized by high intakes of wholegrains and fresh fruit and low intakes of take-away foods and soft drinks, was associated with higher odds of having a healthy metabolic profile [20]. Similar findings for a 'healthy' DP were observed in a national longitudinal study in Chinese adults [53] and a representative community sample of Lebanese adults [54] but were mixed in a prospective study of UK males [56]. Our DPs were derived to explain the maximum variation in dietary energy density, SFA: PUFA, and total sugars; it is likely that a DP that explained other nutrient intakes, as well as a DP derived using other methodologies, may show different associations with cardiometabolic health.

Observed associations between DP-2 and cardiometabolic health outcomes requires further investigation. Positive correlations with all response variables resulted in DP-2 food groups that were less consistent with a 'healthy' or 'unhealthy' diet, i.e. DP-2 was high in both added sugar and fruit intake and low in fish, alcohol and non-whole grain cereals. Although other studies have used a ratio of SFA:PUFA [15] and total sugars, [14] the use of a ratio and a lack of specificity of sugar type (added vs natural) may have limited the interpretation of DP-2. Moreover, this may partly explain why we observed inverse associations with both HDL-cholesterol and DBP. Given that RRR derives DPs that best represent the chosen response variables, investigation of alternative response variables is needed to better understand the role of RRR-derived DPs in cardiometabolic heath. In addition, limited RRR research has examined the role of certain individual biomarkers, such as apolipoprotein, which has been linked to better cardiometabolic health using other DP methodologies [57].

Our findings show consistency between two whole-diet based methodologies for identifying associations with anthropometric markers of cardiometabolic health. Foods comprise a complex mixture of nutrients with potentially contrasting associations with cardiometabolic health, thus supporting a whole diet approach. [58] Future studies based on RRR should evaluate the mechanistic role of response variables and the use of comparable methodologies for deriving an overall risk score.

\section{Strengths and limitations}

The present study has a number of strengths. This study was conducted in a large, nationally representative survey of Australian adults. Although the generalizability of our sample may have been limited by non-response bias associated with those who volunteered to provide biological samples, our analyses used survey weightings 
that were specifically designed to account for such bias. Moreover, there was minimal difference in characteristics between the omitted sample and the analytical sample (Additional file 5: Table S4). We derived two whole diet methodologies, which facilitated a comparison between data-driven and dietary adherence-based methodologies within the same population. These scores were derived from two 24-h recalls, thus offering a more accurate estimate of dietary intake than FFQ-based scores [59]. Moreover, the DGI used age and sex-specific cut-offs, thereby increasing the accuracy of diet quality scores across different population groups. A further strength of this study is the evaluation of the role of BMI in the association between diet quality, DPs and cardiometabolic health.

A limitation of this study is its cross-sectional design, which prohibited interpretation of causal relationships. Given that some measures of cardiometabolic health were self-reported, some individuals may have been aware of their poor cardiometabolic health and may have changed their diet as a result. Thus, we cannot discount the possibility of reverse causality. Information on blood pressure or lipid lowering medication was not available and so we were unable to exclude or adjust for this potential confounder. Thus, we cannot discount bias associated with incongruences between blood pressure and lipid data before and after anti-hypertensive and lipid lowering medication use and any associated behavioral changes. While our analyses were adjusted for multiple confounders, including energy misreporting, residual confounding may be a limitation. Moreover, missing data, most notably for biochemical and the second day of dietary recalls, may have introduced bias. Although the timing of 24-h dietary recalls may limit their ability to capture usual intake and seasonal variations in dietary intakes, our use of two 24-h recalls offers an advantage over previous studies based on one day of dietary recall [20] and our research has demonstrated that RRR DPs derived from the average of two days are comparable to those derived using usual intakes [14]. Any seasonal impact on DPs may have influenced smaller food groups, such as stone fruits, but is likely to be minimal in larger food groups, such as brassica vegetables, and in the DGI. Moreover, a seasonal adjustment was also incorporated into the person weights in the NNPAS [27]. Limitations of RRR should also be acknowledged. First, although the food groups are based on AUSNUT 2011-13, the number and definitions of the food groups used in this study may have affected the derived DP. Second, although our choice of response variables was based on published literature the use of different response variables may have resulted in a different DPs. Moreover, RRR derives DPs that closely reflect nutrient intakes or intermediate markers, which may result in DPs less consistent with behavioral patterns compared to factor or cluster analysis. Third, we generated and fitted RRR DP in the same data set. To rule out any effect of over-fitting and to show generalizability of RRR DP, future studies should consider deriving and applying DP in independent data sets. Although we were unable to disaggregate the effect of added sugars from total sugars in our response variable, food group intakes provided information on the foods that characterized the DPs. Prospective studies that consider type 2 diabetes and cardiovascular disease incidence and that compare both diet quality and DP methodologies within the same population are needed.

\section{Implications of findings}

Both diet quality and DP methodologies (DP-1) support healthy eating initiates to improve cardiometabolic health that centre on diets rich in fruits, vegetables, wholegrains and lean meats and/or alternatives and low in processed foods and alcohol. Furthermore, this study provides evidence for the comparability of associations between whole diet measures and cardiometabolic health. This evidence is imperative for the effective integration of diet quality and DP research. As a result, the present findings have the potential to inform the design of future DP-based research that aims to evaluate association with cardiometabolic health.

\section{Conclusions}

Better diet quality and a healthier DP were primarily associated with favorable anthropometric markers of cardiometabolic health. Findings support the need to compare across multiple whole-diet based methodologies, which take into consideration the interaction between foods and nutrients consumed together. The limited associations observed between diet quality, DPs and biochemical cardiometabolic markers warrants further investigation. Studies that evaluate the role of different response variables and that are longitudinal in design are needed to better understand causal relationships between diet and cardiometabolic health.

\section{Additional files}

Additional file 1: Table S1. STROBE-nut: An extension of the STROBE epidemiology. (DOCX 22 kb)

Additional file 2: Table S2. Components and scoring methods of the Dietary Guideline Index (DGI). (DOCX $18 \mathrm{~kb}$ )

Additional file 3: Table S3. Food groups used as predictors in the reduced rank regression analyses $(n=48)$ (DOCX $17 \mathrm{~kb})$

Additional file 4: Figure S1. Directed acyclic graph (DAG) used to help identify the confounder selection for the statistical analysis. (DOCX 189 kb)

Additional file 5: Table S4. Characteristics of adults who were omitted from the analytical sample based on only 1 day of 24-h recall and based on missing covariates and those who were included in the analytical sample. (DOCX $15 \mathrm{~kb}$ )

Additional file 6: Table S5. Factor loadings for reduced rank regression dietary patterns. (DOCX $19 \mathrm{~kb}$ )

Additional file 7: Table S6. Demographic and cardiometabolic characteristics of Australian adults across sex-specific tertiles (T) of each dietary pattern $(n=2121)$. (DOCX $21 \mathrm{~kb})$ 


\section{Abbreviations}

AHS: Australian Health Survey; BMl: Body mass index; DBP: Diastolic blood pressure; DGI: Dietary guideline index; DP: Dietary pattern; FFQ: Food frequency questionnaire; NHMS: National Health Measures Survey; NNPAS: National Nutrition and Physical Activity Survey; PA: Physical activity; SBP: Systolic blood pressure

\section{Acknowledgements}

None

\section{Funding}

KML acknowledges support from the Alfred Deakin Postdoctoral Research Fellowship. SAM is supported by an NHMRC Career Development Fellowship Level 2 (ID1104636).

\section{Availability of data and materials}

The data that support the findings of this study are available from the Australian Bureau of Statistics but restrictions apply to the availability of these data, which were used under license for the current study, and so are not publicly available. Data are however available from the authors upon reasonable request and with permission of the Australian Bureau of Statistics.

\section{Authors' contributions}

The authors' responsibilities were as follows: KML, SM contributed to the research design. KML performed the statistical analysis for the manuscript and drafted the paper. Both authors contributed to a critical review of the manuscript during the writing process. Both authors approved the final version to be published.

\section{Ethics approval and consent to participate}

Ethics approval for the NHMS was granted by the Australian Government Department of Health and Ageing Departmental Ethics Committee.

\section{Consent for publication}

Not applicable

\section{Competing interests}

None of the authors had a personal or financial conflict of interest.

\section{Publisher's Note}

Springer Nature remains neutral with regard to jurisdictional claims in published maps and institutional affiliations.

\section{Received: 12 October 2017 Accepted: 19 January 2018}

\section{Published online: 12 February 2018}

\section{References}

1. World Health Organization. Noncommunicable diseases. http://www.who. int/mediacentre/factsheets/fs355/en/ . Accessed 17 Nov 2017.

2. American Diabetes Association. Management of Dyslipidemia in adults with diabetes. Diabetes Care. 2003;26:s83-6. https:/doi.org/10.2337/diacare.26.2007.S83.

3. Hu FB, Manson JE, Stampfer MJ, Colditz G, Liu S, Solomon CG, Willett WC. Diet, lifestyle, and the risk of type 2 diabetes mellitus in women. N Engl J Med. 2001;345:790-7. https://doi.org/10.1056/NEJMoa010492.

4. Diet, Nutrition and the Prevention of Chronic Diseases. Technical Report Series no. 916. http://www.who.int/dietphysicalactivity/publications/trs916/ en/. Accessed 18 Nov 2017

5. Gakidou E, Afshin A, Abajobir AA, Abate KH, Abbafati C, Abbas KM, Abd-Allah F, Abdulle AM, Abera SF, Aboyans V, et al. Global, regional, and national comparative risk assessment of 84 behavioural, environmental and occupational, and metabolic risks or clusters of risks, 1990-2016: a systematic analysis for the global burden of disease study 2016. Lancet. 2017;390:1345-422. https://doi.org/10.1016/S0140-6736(17)32366-8.

6. Salmerón J, Hu FB, Manson JE, Stampfer MJ, Colditz GA, Rimm EB, Willett WC Dietary fat intake and risk of type 2 diabetes in women. Am J Clin Nutr. 2001; 73:1019-26.

7. Juan J, Liu G, Willett WC, Hu FB, Rexrode KM, Sun Q. Whole grain consumption and risk of ischemic stroke. Results from 2 prospective cohort studies. Stroke. 2017:48:3203-9. https://doi.org/10.1161/strokeaha.117.018979.

8. Imamura F, Micha R, Khatibzadeh S, Fahimi S, Shi P, Powles J, Mozaffarian D. Dietary quality among men and women in 187 countries in 1990 and 2010: a systematic assessment. Lancet Glob Health. 2015;3:e132-42. https://doi. org/10.1016/S2214-109X(14)70381-X.
9. Milte CM, Thorpe MG, Crawford D, Ball K, McNaughton SA. Associations of diet quality with health-related quality of life in older Australian men and women. Exp Gerontol. 2015;64:8-16. https://doi.org/10.1016/j.exger.2015.01.047.

10. Nanri A, Mizoue T, Shimazu T, Ishihara J, Takachi R, Noda M, Iso H, Sasazuki S, Sawada N, Tsugane S, for the Japan Public Health Center-Based Prospective Study G. Dietary patterns and all-cause, cancer, and cardiovascular disease mortality in Japanese men and women: the Japan public health center-based prospective study. PLoS One. 2017;12:e0174848. https://doi.org/10.1371/journal. pone.0174848.

11. George SM, Ballard-Barbash R, Manson JE, Reedy J, Shikany JM, Subar AF, Tinker LF, Vitolins M, Neuhouser ML. Comparing indices of diet quality with chronic disease mortality risk in postmenopausal women in the Women's Health Initiative observational study: evidence to inform National Dietary Guidance. Am J Epidemiol. 2014;180:616-25. https://doi.org/10.1093/aje/kwu173.

12. Hoffmann K, Schulze MB, Schienkiewitz A, Nöthlings U, Boeing $H$. Application of a new statistical method to derive dietary patterns in nutritional epidemiology. Am J Epidemiol. 2004;159:935-44. https://doi.org/ 10.1093/aje/kwh134.

13. Jacobs S, Kroeger J, Schulze MB, Frank LK, Franke AA, Cheng I, Monroe KR, Haiman CA, Kolonel LN, Wilkens LR, et al. Dietary patterns derived by reduced rank regression are inversely associated with type 2 diabetes risk across five ethnic groups in the multiethnic cohort. Curr Dev Nutr. 2017 https://doi.org/10.3945/cdn.117.000620.

14. Livingstone KM, McNaughton S. Dietary patterns by reduced rank regression are associated with obesity and hypertension in Australian adults. $\mathrm{Br}$ J Nutr. 2017; https://doi.org/10.1017/S0007114516004505.

15. Sherafat-Kazemzadeh R, Egtesadi S, Mirmiran P, Gohari M, Farahani SJ, Esfahani FH, Vafa MR, Hedayati M, Azizi F. Dietary patterns by reduced rank regression predicting changes in obesity indices in a cohort study: Tehran lipid and glucose study. Asia Pac J Clin Nutr. 2010;19:22-32.

16. Weikert C, Schulze MB. Evaluating dietary patterns: the role of reduced rank regression. Curr Opin Clin Nutr Metab Care. 2016;19:341-6. https://doi.org/ 10.1097/mco.0000000000000308

17. Alessa HB, Malik VS, Yuan C, Willett WC, Huang T, Hu FB, Tobias DK. Dietary patterns and cardiometabolic and endocrine plasma biomarkers in US women. Am J Clin Nutr. 2016; https://doi.org/10.3945/ajcn.116.143016.

18. Mattei J, Sotres-Alvarez D, Daviglus ML, Gallo LC, Gellman M, Hu FB, Tucker KL, Willett WC, Siega-Riz AM, Van Horn L, Kaplan R. Diet quality and its association with Cardiometabolic risk factors vary by Hispanic and Latino ethnic background in the Hispanic community health study/study of Latinos. J Nutr. 2016;146:2035-44. https://doi.org/10.3945/jn.116.231209.

19. McNaughton SA, Dunstan DW, Ball K, Shaw J, Crawford D. Dietary quality is associated with diabetes and cardio-metabolic risk factors. J Nutr. 2009;139:734-42. https://doi.org/10.3945/jn.108.096784

20. Bell L, Edwards S, Grieger J. The relationship between dietary patterns and metabolic health in a representative sample of adult Australians. Nutrients. 2015;7:5295

21. Frazier-Wood AC, Kim J, Davis JS, Jung SY, Chang S. In cross-sectional observations, dietary quality is not associated with CVD risk in women; in men the positive association is accounted for by BMI. Br J Nutr. 2015:113:1244-53. https://doi.org/10.1017/S0007114515000185.

22. Liese AD, Krebs-Smith SM, Subar AF, George SM, Harmon BE, Neuhouser ML, Boushey CJ, Schap TE, Reedy J. The dietary patterns methods project: synthesis of findings across cohorts and relevance to dietary guidance. J Nutr. 2015;145:393-402. https://doi.org/10.3945/jn.114.205336.

23. Oude Griep LM, Wang H, Chan Q. Empirically-derived dietary patterns, diet quality scores, and markers of inflammation and endothelial dysfunction. Curr Nutr Rep. 2013;2:97-104. https://doi.org/10.1007/s13668-013-0045-3.

24. Manios $Y$, Kourlaba G, Grammatikaki E, Androutsos O, loannou E, Roma-Giannikou E. Comparison of two methods for identifying dietary patterns associated with obesity in preschool children: the GENESIS study. Eur J Clin Nutr. 2010:64:1407. https://doi.org/10.1038/ejcn.2010.168.

25. Nettleton JA, Steffen LM, Schulze MB, Jenny NS, Barr RG, Bertoni AG, Jacobs DR. Associations between markers of subclinical atherosclerosis and dietary patterns derived by principal components analysis and reduced rank regression in the multi-ethnic study of atherosclerosis (MESA). Am J Clin Nutr. 2007;85:1615-25.

26. Rodríguez-Monforte M, Sánchez E, Barrio F, Costa B, Flores-Mateo G. Metabolic syndrome and dietary patterns: a systematic review and meta-analysis of observational studies. Eur J Nutr. 2017;56:925-47. https://doi.org/10.1007/s00394-016-1305-y. 
27. Australian Health Survey: Users' Guide, 2011-13, Catalogue No 4363.0.55. 001. http://www.abs.gov.au/ausstats/abs@.nsf/Lookup/4363.0.55. 001Chapter1002011-13. Accessed 1 Aug 2017

28. World Health Organization.Obesity and overweight. http://www.who.int/ mediacentre/factsheets/fs311/en/. Accessed 5 Sept 2017.

29. Friedewald WT, Levy RI, Fredrickson DS. Estimation of the concentration of low-density lipoprotein cholesterol in plasma, without use of the preparative ultracentrifuge. Clin Chem. 1972;18:499-502.

30. Wijndaele K, Healy GN, Dunstan DW, Barnett AG, Salmon J, Shaw JE, Zimmet PZ, Owen N. Increased Cardiometabolic risk is associated with increased TV viewing time. Med Sci Sports Exerc. 2010;42:1511-8. https://doi.org/10.1249/MSS.0b013e3181d322ac.

31. Bliss R. Researchers produce innovation in dietary recall. Agric Res. 2004;52:10-2.

32. AUSNUT 2011-13: Australian Food, Supplement and Nutrient Database. http://www.foodstandards.gov.au/science/monitoringnutrients/ausnut/ Pages/about.aspx. Accessed 11 Sept 2017

33. National Health and Medical Research Council. Australian Dietary Guidelines. Canberra: National Health and Medical Research Council; 2013.

34. Livingstone KM, McNaughton SA. Diet quality is associated with obesity and hypertension in Australian adults: a cross sectional study. BMC Public Health. 2016;16:1037. https://doi.org/10.1186/s12889-016-3714-5.

35. Thorpe M, Milte C, Crawford D, McNaughton S. A revised Australian dietary guideline index and its association with key Sociodemographic factors, health behaviors and body mass index in Peri-retirement aged adults. Nutrients. 2016:8:160.

36. National Health and Medical Research Council. 2013. Educator Guide: Eat for Health. Canberra: National Health and Medical Research Council.

37. Waijers PMCM, Feskens EJM, Ocké MC. A critical review of predefined diet quality scores. Br J Nutr. 2007;97:219-31. https://doi.org/10.1017/ S0007114507250421.

38. Wirfält E, Drake I, Wallström P. What do review papers conclude about food and dietary patterns? Food Nutr Res. 2013;57. https://doi.org/10.3402/fnr. v57i0.20523.

39. da Silva BDP, Neutzling MB, Camey S, Olinto MTA. Dietary patterns and hypertension: a population-based study with women from southern Brazil. Cad Saúde Pública. 2014;30:961-71.

40. Johnson L, Mander AP, Jones LR, Emmett PM, Jebb SA. Energy-dense, low-fiber, high-fat dietary pattern is associated with increased fatness in childhood. Am J Clin Nutr. 2008;87:846-54.

41. Schulze MB, Hoffmann K, Kroke A, Boeing H. An approach to construct simplified measures of dietary patterns from exploratory factor analysis. Br J Nutr. 2003:89:409-18. https://doi.org/10.1079/BJN2002778.

42. Australian Standard Classification of Education (ASCED) 2001. http://www. abs.gov.au/AUSSTATS/abs@.nsf/ProductsbyCatalogue/ B49672F95CD93ABECA2570B30005BFE1. Accessed 16 Oct 2017.

43. Statistical Geography Volume 1 - Australian Standard Geographical Classification (ASGC) 2006. http://www.abs.gov.au/AUSSTATS/abs@.nsf/Lookup/ 1216.0Main+Features1 Jul\%202006?OpenDocument. Accessed 15 Sept 2017.

44. Huang TTK, Roberts SB, Howarth NC, McCrory MA. Effect of screening out implausible energy intake reports on relationships between diet and BMI. Obes Res. 2005;13:1205-17. https://doi.org/10.1038/oby.2005.143.

45. Gopinath B, Rochtchina E, Flood VM, Mitchell P. Diet quality is prospectively associated with incident impaired fasting glucose in older adults. Diabet Med. 2013;30:557-62. https://doi.org/10.1111/dme.12109.

46. Nicklas TA, O'Neil CE, Fulgoni VL. Diet quality is inversely related to cardiovascular risk factors in adults. J Nutr. 2012;142:2112-8. https://doi.org/ 10.3945/jn.112.164889.

47. Ford ES, Giles WH, Dietz WH. Prevalence of the metabolic syndrome among us adults: findings from the third national health and nutrition examination survey. JAMA. 2002;287:356-9. https://doi.org/10.1001/jama.287.3.356.

48. Smith KJ, Blizzard L, McNaughton SA, Gall SL, Dwyer T, Venn AJ. Takeaway food consumption and cardio-metabolic risk factors in young adults. Eur J Clin Nutr. 2012;66:577-84

49. Heidemann C, Hoffmann K, Spranger J, Klipstein-Grobusch K, Möhlig M, Pfeiffer AFH, Boeing $\mathrm{H}$. A dietary pattern protective against type 2 diabetes in the European prospective investigation into cancer and nutrition (EPIC)—Potsdam study cohort. Diabetologia. 2005;48:1126-34. https://doi.org/10.1007/s00125-005-1743-1.

50. Liese AD, Weis KE, Schulz M, Tooze JA. Food intake patterns associated with incident type 2 diabetes: the insulin resistance atherosclerosis study. Diabetes Care. 2009;32:263-8. https://doi.org/10.2337/dc08-1325.
51. McNaughton SA, Mishra GD, Brunner EJ. Dietary patterns, insulin resistance, and incidence of type 2 diabetes in the Whitehall II study. Diabetes Care. 2008;31:1343-8. https://doi.org/10.2337/dc07-1946.

52. Johns DJ, Lindroos A-K, Jebb SA, Sjöström L, Carlsson LMS, Ambrosini GL. Dietary patterns, cardiometabolic risk factors, and the incidence of cardiovascular disease in severe obesity. Obesity. 2015;23:1063-70. https://doi.org/10.1002/oby.20920.

53. Li M, Shi Z. Dietary pattern during 1991-2011 and its association with cardio metabolic risks in Chinese adults: the China health and nutrition survey. Nutrients. 2017;9:1218. https://doi.org/10.3390/nu9111218.

54. Nasreddine L, Tamim H, Itani L, Nasrallah MP, Isma'eel H, Nakhoul NF, Abou-Rizk J, Naja F. A minimally processed dietary pattern is associated with lower odds of metabolic syndrome among Lebanese adults. Public Health Nutr. 2017;21:160-71. https://doi.org/10.1017/S1368980017002130.

55. Mathew H, Farr OM, Mantzoros CS. Metabolic health and weight: understanding metabolically unhealthy normal weight or metabolically healthy obese patients. Metabolism. 2016;65:73-80. https://doi.org/10.1016/j. metabol.2015.10.019.

56. Mertens E, Markey O, Geleijnse JM, Givens DI, Lovegrove JA. Dietary patterns in relation to cardiovascular disease incidence and risk markers in a middle-aged British male population: data from the Caerphilly prospective study. Nutrients. 2017:9:75. https://doi.org/10.3390/nu9010075.

57. Chiu S, Bergeron N, Williams PT, Bray GA, Sutherland B, Krauss RM. Comparison of the DASH (dietary approaches to stop hypertension) diet and a higher-fat DASH diet on blood pressure and lipids and lipoproteins: a randomized controlled trial. Am J Clin Nutr. 2016;103:341-7. https://doi.org/ 10.3945/ajcn.115.123281.

58. Siri-Tarino PW, Chiu S, Bergeron N, Krauss RM. Saturated fats versus polyunsaturated fats versus carbohydrates for cardiovascular disease prevention and treatment. Annu Rev Nutr. 2015;35:517-43. https://doi.org/ 10.1146/annurev-nutr-071714-034449.

59. Shim J-S, Oh K, Kim HC. Dietary assessment methods in epidemiologic studies. Epidemiol Health. 2014;36:e2014009. https://doi.org/10.4178/epih/ e2014009.

\section{Submit your next manuscript to BioMed Central and we will help you at every step:}

- We accept pre-submission inquiries

- Our selector tool helps you to find the most relevant journal

- We provide round the clock customer support

- Convenient online submission

- Thorough peer review

- Inclusion in PubMed and all major indexing services

- Maximum visibility for your research

Submit your manuscript at www.biomedcentral.com/submit 